\title{
The Effects of Information and Communication Technology on Health Service Delivery at Tafo Government Hospital
}

\author{
Kennedy Addo ${ }^{*}$, Pabbi Kwaku Agyepong² \\ ${ }^{1}$ Garden City University College, Kumasi, Ghana \\ ${ }^{2}$ Department of Computer Science, Kwame Nkrumah University of Science and Technology, Kumasi, Ghana \\ Email: ^kenaddo90@yahoo.com, kwakupabbi@yahoo.co.uk
}

How to cite this paper: Addo, K. and Agyepong, P.K. (2020) The Effects of Information and Communication Technology on Health Service Delivery at Tafo Government Hospital. E-Health Telecommunication Systems and Networks, 9, 33-48. https://doi.org/10.4236/etsn.2020.93003

Received: August 4, 2020

Accepted: September 12, 2020

Published: September 15, 2020

Copyright (c) 2020 by author(s) and Scientific Research Publishing Inc. This work is licensed under the Creative Commons Attribution International License (CC BY 4.0).

http://creativecommons.org/licenses/by/4.0/

\section{(c) (i) Open Access}

\begin{abstract}
This study sought to find out the effects of Information and Communication Technology (ICT) on health service delivery at Tafo Government Hospital. A descriptive survey design was used. Data were collected through the use of semi-structured questionnaire and administered to 50 respondents where stratified random sampling technique was used by ranking position as strata. Data were analyzed using descriptive statistics. From the findings, $56 \%$ of the respondents overwhelmingly agreed to the fact that the applications of ICT provide quicker medical diagnoses, reduced workload among users, improvement in patients' waiting time and information accessibility. Nonetheless, $72 \%$ bemoaned lack of ICT infrastructure, poor ICT network concerns coupled with that insufficient knowledge on the use of ICT could impede the impact of ICT in quality service delivery. This could be deduced from the findings that ICT improves collaboration and clinical decision support in facilitating clinical work flow integration among nurses and other medical professionals. Moreover, the findings above affirm the fact that without electricity, ICT infrastructure, insufficient skills and technical knowledge in dealing with ICT innovations, it is impossible to successfully adopt ICT resources in health care delivery. The above findings show that the majority of healthcare professional generally had a positive attitude towards ICT prospects as they rated their skill as fairly well. The study recommends that the Ministry of Health plays a supporting role by investing in health care ICT.
\end{abstract}

\section{Keywords}

Information and Communication Technology, Information Technology,

Health Care Professionals, Electronic Health Records,

Quality of Care 


\section{Introduction}

\subsection{Background to the Study}

The adoption of Information Communication Technology (ICT) among general practitioners is to provide access to the health services for the citizens [1]. ICT resources have improved level of patients' safety and outcome [2] Furthermore, the use of sophisticated equipment has improved the aspect of progressively updating the patients about their medical status [3].

The recent increasing burden of health care cost has been regarded as the primary contemporary issue affecting the health care industry in several nations of the world.

Through the application of ICT resources in the healthcare sectors, hospitals have been able to reduce their operational and other associated costs [4].

In the developed countries the phenomenon of ageing population is evident with predictions of $60 \%$ hikes in the overall costs targeted at such group of people. The application of ICT in health care helps address the deficit of physicians in both developing and advanced countries. A good example is Telemedicine and other e-health applications. ICT has potential if properly deployed to lower costs of health care, while opening up new modalities for patient treatment and welfare [5].

Undoubtedly, ICT resources adoption has contributed significantly to better quality of care. The increased use of ICT resources in hospitals has helped improved the knowledge level of the patients [6]. This is because through the use of the computers or monitors, digital ICT tools, the patients have a chance of grasping the visual perspective of the health status. Moreover, the ICT integrated system is critical to patients' diagnosis and the reduction of medical errors has gone a long way in holistically improving the level and quality of healthcare outcomes and patients' safety [2]. Other aspects of quality in the health sectors are affordability, newer medical and effective medication [7]. According to [8], improved health systems are fundamental in ensuring improved citizen's welfare and of nations as well.

This is attested by a study conducted in Bangladesh by [9], where a 25 year old female doctor said, using an ICT tool makes her more efficient and "make her work easier". These improved efficiencies have the likelihood to result in improved employee morale and maintenance. Similarly, evidence suggests that e-health tools and for that matter ICT have positive effect on users [10]. Thus users of ICT are more inclined to become well-informed, better supported, and have improved behavioural outcomes, as compared to non-users of ICT, in the same health facility. Imaging technologies feeds a number of emerging trends with potential application in ICT's medical instruments and healthcare clearly and has improved and contributed to more affordable wide range of medical imaging, remote diagnostic and even treatment.

Health care professionals acknowledge several challenges to their poor ICTs utilization in daily activities in working. The literature analysis on ICT adoption 
resources in health service standards revealed that the slow pace of the adoption of standards (both by developed and developing nations) is due to several factors.

\subsection{Statement of the Problem}

According to Institute of Economic Affairs (IEA), 1.5 billion people worldwide lack access to electricity. Without electricity, it is impossible to successfully adopt ICT resource strategy. According to [11], many towns in Kenya have remote areas without access to electricity.

In addition, electricity can enhance social connectivity through the shared experiences of television, use of cellular phones [12]. Moreover, where ICT infrastructures are in place, they are neither standardized nor based on common platforms, making it difficult for them to interoperate. There is no proper interoperability that supports health information systems due to lack of cost-effective use of ICT applications [13]. ICT infrastructure pertinently affects adoption of ICT [14]. According to a study conducted by [14], ICT infrastructure has dominated most research in health care facilities especially in the health sectors of most countries. According to a study conducted by Acheampong, hospitals in Ghana lack appropriate technologies, computer systems/utilities that are relevant to improving healthcare services [15].

The problems that refute the implementation of ICT in the facility included but not limited to issues of stable electricity supply, which is one of the fundamental problems that pose a threat to the full functionality of the system. It is impossible to successfully adopt ICT resource strategy where there is no adequate supply of power and that is the current picture at Tafo Government hospital. Moreover, ICT infrastructure including computers and other sophisticated hardware and software among others is lacking and the problems of standardized and interoperability make it more difficult to have a resilient health care system.

Illiteracy has largely affected ICT resource strategy adoption in the health care sector.

Culture may influence the level of illiteracy in technology in information and even in other field [16]. Health care professionals are not technical nor are they ICTs experts, hence for them to operate the systems they need as much training and support for the systems and they might be reluctant to adopt the systems if they are not given adequate support [17]. [18] attributes low adoption of ICT resource strategy among developing countries to lack of computer skills amongst the clinicians.

Illiteracy in terms of ICT proficiency has also retarded the smooth running of the system as many of the health care professionals lack the requisite knowledge and skills in the use of ICT and this one way or the other compromises quality of care.

Lack of finances and equipment resources is a challenge to public health institutions in the adoption of modern technologies. In developing countries qual- 
ity of healthcare services is low due to poor public resource management [19]. [11] describes financial management is an art and a science in any industry, but health care is particularly challenging because industry changes so fast. The cost of training employees (healthcare professionals) has continued to be a key issue in adoption of ICT resources in Kenya. Besides, healthcare facilities do not develop training plans.

This study seeks to assess the effects of Information and Communication Technology on health service delivery at Tafo Government Hospital.

One of the major challenges undermining ICT application is the issue of finance. The adoption of modern technologies requires huge financial commitment and investment to make it workable and ultimately harness the full potential of end-users.

\subsection{Proposed System}

- Improved health information and communication exchange among health care professionals and patients

- Facilitate and promote quality of care through efficient and effective health service delivery

- Provision of adequate ICT infrastructure to encourage acceptance and utilization.

The section below explains the study questions, objective and significance. The methodology section shows the study area, design, population, sampling and sampling techniques, data collection methods and data analysis used. Findings, results, conclusions and recommendations are broadly discussed.

\subsection{Research Questions}

The research sought to address the following research questions;

1) What is the knowledge and attitude of staff towards the use of ICT at Tafo Government Hospital?

2) How efficient and effective is the use of ICT at Tafo Government Hospital?

3) What are the factors opposed against the application of ICT at Tafo Government Hospital?

\subsection{Study Objectives}

The study is intended to assess the effects of Information and Communication Technology on health service delivery at Tafo Government Hospital. It also aims at determining the knowledge and attitude of staff towards the use of ICT. It also reviews the efficiency and effectiveness use of ICT and the challenges of ICT in the health service delivery.

\subsection{Study Significance}

Over the last decade, the inclusion of Information and Communication Technology (ICT) has helped develop new ways of providing efficient and secure 
healthcare. This has resulted in a rapid increase in the utilization of ICT application in the health sector [1].

Information dissemination has been very scanty due to low level of ICT in the delivery of health services in the Tafo Government hospital. This has contributed significantly to the burden of morbidities and increased mortalities in the district and its environs. The research seeks to contribute to the course of health delivery by advocating for ICT interoperability in the facility as the impetus to address the gaps in the delivery of effective health care. This could help facilitate an improved patient and doctors' rapport and conversely lead to better care outcomes and therapeutic communications. This will indirectly decipher into an improvement in the health status of the country.

\section{Research Methodology}

\subsection{Study Area}

The study was carried out in Tafo Government Hospital; a primary hospital located in Manhyia North Sub-metro bounded on the north by Aware, on the south by Subin, East-Manhyia South and on the West Bantama. It was established in 1976. The sub-metro has a population of 252,983 which is $16 \%$ of $\mathrm{Ku}$ masi Metro Population. Tafo town is divided into zones and these include Mile three, Four miles. The hospital serves the entire community and its nearby towns.

Tafo Government Hospital was selected based on its proximity, easy accessibility, cooperation and cost.

The staff strength of the hospital is 177 including Clinical and paramedics. The hospital renders a 24 hour services which include the following; Out-Patient Department Services, Inpatient Services, Maternal services, Surgery, Specialist Services (Skin and Obstetrics/Gynaecology), Laboratory, X-ray and Scan, Public Health Services (ANC and PNC).

\subsection{Study Design}

The study adopted descriptive survey design because, it focuses on observation and perception of the existing situation, describes and interprets the issues, conditions, practice or relationship that exist; views, belief and attitude that are held, processes that are going on and trends that are developing. The research approach is purely quantitative with a questionnaire survey method.

\subsection{Study Population and Sample}

The population for the study comprised of all registered health practitioners in Tafo Government hospital. The target population of this study was the entire health practitioners of the surveyed institution. The study was limited to doctors, nurses, midwives and other health practitioners in Tafo Government hospital.

Sample size for this research work based on some major departments/units (including specialty clinic, accident and emergency unit, in-patients' and 
out-patients' servives, obstetrics and gynecology). The population of the selected major department/unit study comprised of the 100 medical/health practitioners in the institutions sampled. However, in order to have reliable and manageable size, the sample size of $50 \%$ was considered. This method was used to select 50 respondents as sample size for the study by using stratified random sampling technique by ranking/position as strata

\subsection{Data Collection}

Study questionnaires were used due to their characteristics that they can capture large amounts of data which may contain both quantitative and qualitative data. Both open ended and closed ended questionnaire were used to collect data for the study.

The questionnaire were divided into five sections whereby section A contained questions which deals with the general particulars and background information of the respondents while other sections address the research objectives of the study.

The demographic characteristics of the respondents recruited to be part of the study were noted as shown in Table 1.

\subsection{Validity and Reliability}

After administering the instruments to the selected respondents, the data obtained was a true reflection of the variables under study.

In order to ensure research reliability, responses were measured in the same way in repeated tests and guaranteed the same results.

\subsection{Data Analysis Technique}

For the purpose of this study and to achieve accuracy in processing data collected, the use of computer aided statistical package for social science version 20.0 (SPSS) was engaged.

The data obtained from the questionnaire were edited and subjected to Statistical Data Analysis. A broad technique of data analysis was carried out in order to elucidate the result of the findings using unilabiate analyses which deal with tables and charts. It is a single variable analysis which describes the necessary features of the sets of data. The data were analyzed using frequency, percentages, bar chart and graph coupled with write-ups for proper interpretations.

\section{Results and Findings}

\subsection{Required Knowledge and Attitude in Using ICT Resources}

The respondents were ranked according to their knowledge level, attitude and interactions towards the application of ICT in health care delivery and the responses were noted as shown in Table 2.

In order to answer the question, the respondents were asked to give ratings to the required knowledge and attitude in using ICT resources as follows; 24 (48\%) 
of the respondent claimed to have used ICT systems for the years spanning between 6 - 10 years, 17 (34\%) between 1 - 5 years, $6(12 \%)$ between 11 - 15 years, 2 (4\%) ranging between 16 years and above while $1(2 \%)$ refused to ascribe answer to the aforementioned question. Generally, 49 (98\%) of the respondents pointed out that they use ICT tools such as electronic health records in their daily routines while 1 (2\%) did not answer this question. Nonetheless, 34 (68\%) of the responses showed the application of ICT in their daily routines, $8(16 \%)$ once a week, $5(10 \%)$ claimed other days, $2(4 \%)$ occasionally and $2(1 \%)$ shirked away from providing answer to the question.

Table 1. Demographic profile of the study respondents.

\begin{tabular}{|c|c|c|c|}
\hline Variable & Value & Frequency $(N=50)$ & Percent (\%) \\
\hline \multirow[t]{2}{*}{ Gender } & Female & 28 & 56 \\
\hline & Male & 22 & 44 \\
\hline \multirow[t]{4}{*}{ Age } & $26-35 \mathrm{yrs}$ & 31 & 62 \\
\hline & $36-45 \mathrm{yrs}$ & 12 & 24 \\
\hline & $46-54 \mathrm{yrs}$ & 1 & 2 \\
\hline & Below 25 yrs & 6 & 12 \\
\hline \multirow[t]{4}{*}{ Staff Category } & Medical doctors & 4 & 8 \\
\hline & Midwives & 13 & 26 \\
\hline & Nurses & 20 & 40 \\
\hline & Other health practitioners & 13 & 26 \\
\hline \multirow[t]{5}{*}{ Length of working } & No response & 1 & 2 \\
\hline & $1-3 \mathrm{yrs}$ & 18 & 36 \\
\hline & $4-6 y r s$ & 15 & 30 \\
\hline & $6-10 \mathrm{yrs}$ & 14 & 28 \\
\hline & Above 10yrs & 2 & 4 \\
\hline \multirow[t]{3}{*}{ Nationality } & No response & 1 & 2 \\
\hline & Ghanaian & 48 & 96 \\
\hline & Non-Ghanaian & 1 & 2 \\
\hline \multirow[t]{3}{*}{ Religion } & No response & 2 & 4 \\
\hline & Christianity & 41 & 82 \\
\hline & Islamic & 7 & 14 \\
\hline \multirow[t]{2}{*}{ Marital status } & Married & 27 & 54 \\
\hline & Single & 23 & 46 \\
\hline \multirow[t]{4}{*}{ Educational level } & No response & 1 & 2 \\
\hline & Bachelor degree & 19 & 38 \\
\hline & Diploma & 28 & 56 \\
\hline & Master degree & 2 & 4 \\
\hline
\end{tabular}

Source: Fieldwork, 2020. 
Table 2. Required knowledge and attitude in using ICT resources.

\begin{tabular}{|c|c|c|c|}
\hline Variable & Value & Frequency $(N=50)$ & Percent $(\%)$ \\
\hline \multirow{5}{*}{ Years spent in ICT use } & No response & 1 & 2 \\
\hline & $1-5 \mathrm{yrs}$ & 17 & 34 \\
\hline & $11-15 \mathrm{yrs}$ & 6 & 12 \\
\hline & $6-10 \mathrm{yrs}$ & 24 & 48 \\
\hline & Above 16 yrs & 2 & 4 \\
\hline \multirow{2}{*}{ ICT tools used } & No response & 1 & 2 \\
\hline & Yes & 49 & 98 \\
\hline \multirow{5}{*}{ Mode of ICT usage } & No response & 1 & 2 \\
\hline & Everyday & 34 & 68 \\
\hline & Once a week & 8 & 16 \\
\hline & Once in two weeks & 2 & 4 \\
\hline & Other & 5 & 10 \\
\hline \multirow{4}{*}{$\begin{array}{l}\text { Attendance on } \\
\text { ICT programs }\end{array}$} & No response & 7 & 14 \\
\hline & Conferences & 3 & 6 \\
\hline & Formal training & 20 & 40 \\
\hline & Workshop/Seminars & 20 & 40 \\
\hline \multirow{6}{*}{ Last training on ICT } & No response & 2 & 4 \\
\hline & $1-2$ yrs ago & 16 & 32 \\
\hline & $1-6$ months ago & 3 & 6 \\
\hline & $6-12$ months ago & 12 & 24 \\
\hline & More than 2 yrs & 10 & 20 \\
\hline & Never & 7 & 14 \\
\hline \multirow{5}{*}{ Skill level with ICT Use } & No response & 1 & 2 \\
\hline & Excellent & 15 & 30 \\
\hline & Fair & 7 & 14 \\
\hline & Good & 15 & 30 \\
\hline & Very Good & 12 & 24 \\
\hline
\end{tabular}

Source: Fieldwork, 2020.

Respondents were also required to ascertain whether they had gone through some level of ICT training prior to being exposed to the rudiments of ICT. Moreover, 20 (40\%) of the respondents asserted to have ever attended event on the use of ICT through formal training, 20 (40\%) through workshops/seminars, $3(6 \%)$ through conferences while the remaining 7 (14\%) did not answer this question. Moreover, with respect to the respondents number of years exposure to ICT and its applications, 16 (32\%) indicated that they last attended event on ICT use within the last 1 - 2 years ago, 12 (24\%) 6 - 12 months ago, 10 (20\%) more than 2 years ago, 7 (14\%) claimed to have never attended event on ICT use before, 3 (6\%) 1 - 6 months ago while the remaining $2(4 \%)$ failed to provide 
answer to the above-named question. Besides, respondents rated their skills in ICT as follows; 15 (30\%) as good and excellent respectively, $12(24 \%)$ as very good, 7 (14\%) as fair while remaining $1(2 \%)$ did not answer this question.

The findings from the study indicate that the staff has appreciable knowledge and good attitudes towards the applications of ICT in health care delivery.

The respondents indicated that ICT facilitates quicker access to medical diagnoses as shown in Figure 1.

The majority of respondents asserted that ICT enhances doctor-patient rapport and improves quality of health care delivery as shown in Figure 2.

From Figure 1 and Figure 2, it depicts that out of 50 respondents, 28 (56\%) of them agreed to the fact that ICT impact quality of care by providing quicker access to medical diagnoses, whereas others representing 13 (26\%) strongly agreed, $5(10 \%)$ disagreed to the assertion that ICT is an enabler in promoting quality health service delivery. However, the remaining 4 (8\%) were on the neutral grounds and did not state their position with regards to the numerous advantages ICT having on quality health care.

It could also be deduced from Figure 2 that both 15 (30\%) of the respondents were either on the neutral ground and in agreement to the fact that ICT enhances doctor-patient rapport, 12 (24\%) disagreed, 7 (14\%) strongly agreed while the remaining $1(2 \%)$ strongly disagreed to the belief that ICT is an impetus to improving their work.

On other hand, most of the respondents asserted that ICT serves as enabler that facilitates diagnosis and treatment as shown in Figure 3.

The general benefit of the implemented system to the facility as noticeable in all the interviews conducted, included the system's ability to improve health care as it be could seen from Figure 2 below that $29(58 \%)$ of the respondents agreed to the fact that it facilitates consultation, diagnosis and treatment among health care providers and $10(20 \%)$ strongly agreed, 6 (12\%) disagreed and 5 (10\%) were neutral in their assertion on the impact of ICT in the facility.

The findings reveal that majority of the respondents is in agreement of the fact that ICT support their work.

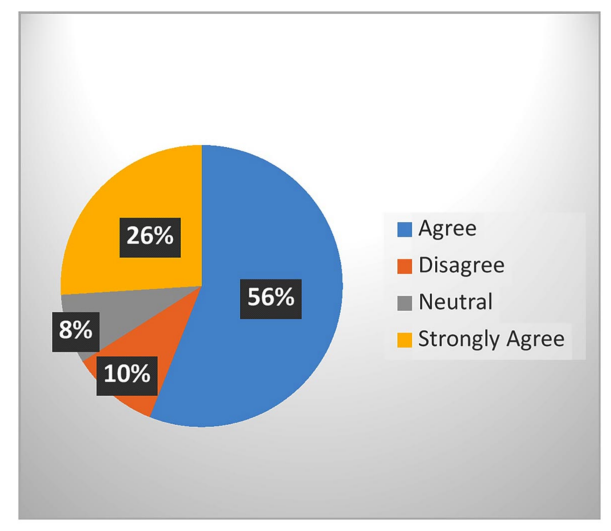

Figure 1. ICT provides quicker access to medical diagnoses. 


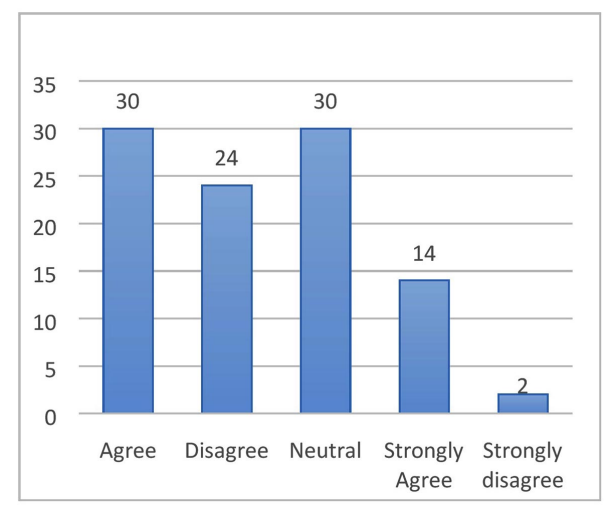

Figure 2. ICT improves doctor-patient rapport.

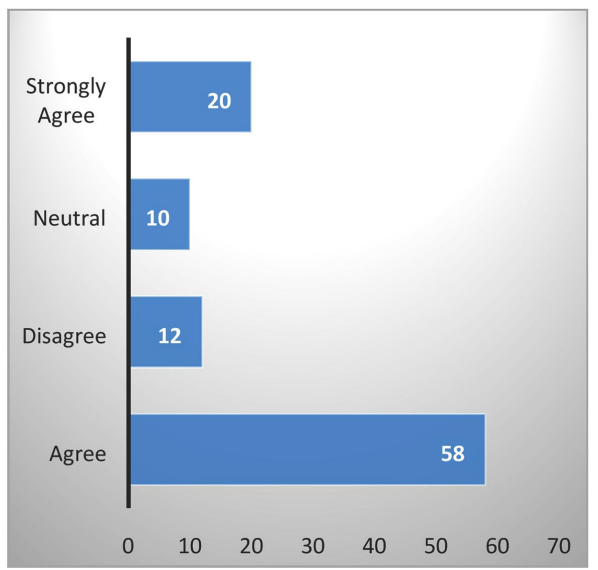

Figure 3. ICT facilitates diagnosis and treatment.

\subsection{Barriers to the Application of ICT Resources}

The respondents view regarding the barriers that hamper the full functionality of ICT in the facility were affirmed as shown in Table 3.

The following were identified by the respondents as the main challenges hindering implementation of ICT systems in health care delivery; lack of ICT facilities (inadequate computers, poor network concerns), insufficient knowledge on how to use ICT resources, inadequate staff training, unstable power supply, and failure of equipment (software and hardware) among others. It could be deduced from the data that $32(64 \%)$ agreed to the fact that lack of proper training affected them in their quest to effectively use the adopted system, whereas $9(18 \%)$ strongly agreed to this fact, 6 (12\%) disagreed, 2 (4\%) were neutral while 1 (2\%) strongly disagreed to the above as contributing factors hampering the smooth running of ICT in health care delivery.

Nonetheless, 33 (66\%) indicated that lack of ICT infrastructure could be an obstruction to the application of ICT, 12 (24\%) strongly agreed to the above mentioned fact while the remaining $5(10 \%)$ disagreed with the above assertion. Again, 36 (72\%) agreed that insufficient knowledge on ICT, 10 (20\%) strongly 
agreed, $3(6 \%)$ were in disagreement regarding the challenges compromising the effective use of ICT while the remaining 1 (2\%) strongly disagreed with the above statement.

In spite of the above challenges opined by the respondents, $24(48 \%)$ on the other hand, confirmed that increased work load hinder the effective use of ICT, $16(32 \%)$ disagreed with the above assertion while the remaining $10(20 \%)$ strongly disagreed in this regard.

Table 3. Barriers to the application of ICT resources at Tafo Government Hospital.

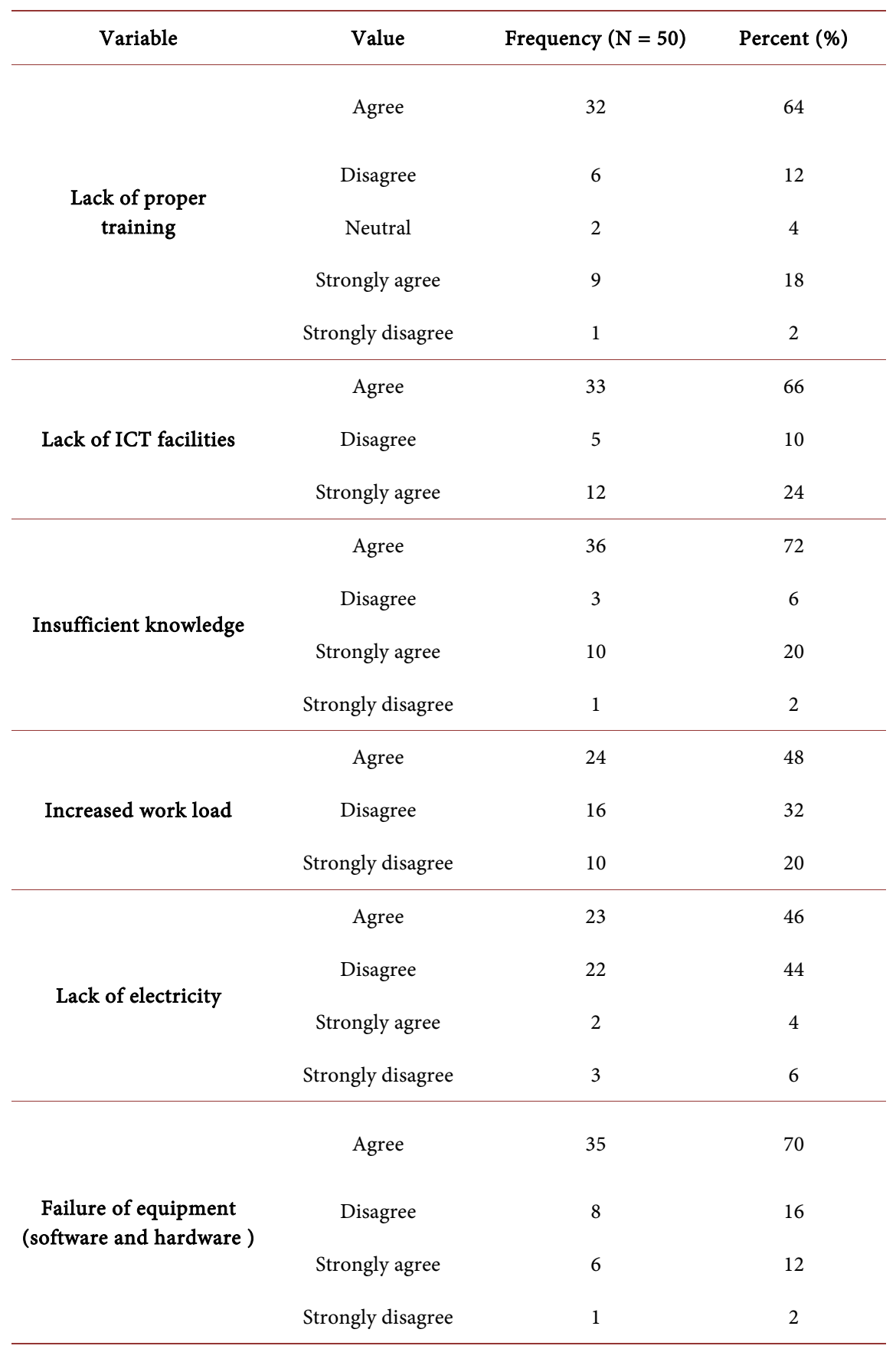

Source: Fieldwork, 2020. 
The respondents also identified intermittent power supply as a major barrier associated with the systems' implementation. In sharing their views and sentiments, they emphasized this does disrupt their workflow and admitted the energy crisis in the country has a negative effect on the systems' stability and functionality. This is strongly supported by their assertion as $23(46 \%)$ agreed that unstable power supply serve as a barrier toward ICT application in healthcare, $22(44 \%)$ disagreed to this fact stressing that power supply has been quite stable recently, $3(6 \%)$ strongly disagreed while the remaining $2(4 \%)$ strongly agreed to the above issue. Nevertheless, 35 (70\%) agreed to the fact that failure of equipment including breakdown of hardware and software are detrimental to the effective use of the system whereas 8 (16\%) disagreed, 6 (12\%) strongly agreed while the remaining 1 (2\%) strongly disagreed.

The finding of the study has reviewed that erratic power supply coupled with faulty equipment has been noted by the respondents as the major obstruction to the health facility, hence compromising quality of care.

\section{Discussion}

Theoretical data concerning the above literature reviewed and its empirical data obtained from the field of this research work are discussed with emphasis on the research objectives.

\subsection{Required Knowledge and Attitude in Using ICT Resources}

The majority of the respondents depicting $40 \%$ indicated they have ever attended event on ICT development through formal training, and other related workshops/ seminars. A significant number of the respondents representing 43 did not answer this question because they claimed to be proficient in the use ICT and other applications. Furthermore, 15 respondents being 30\% rated their skills in ICT as good and excellent respectively. The above findings show that the majority of healthcare professional generally had positive attitude towards ICT prospects. A number of studies have assessed attitudes of healthcare professionals and concluded that they have positive attitudes towards ICT [20]. According to both studies conducted by [21], in 2016, the majority of care providers believed that ICT resources in healthcare facilities increase the quality of care and treatment.

\subsection{Efficient and Effective Use of ICT Resources}

From the findings, $56 \%$ of the respondents overwhelmingly agreed to the fact that the applications of ICT provide quicker medical diagnoses and information accessibility. This could be deduced from the findings that ICT improves collaboration and clinical decision support in facilitating clinical work flow integration among nurses and other medical professionals. The above findings are consistent with [22] who asserted that workflow among the various healthcare entities is improved upon by the use of ICT resources and promotes patients' satis- 
faction.

\subsection{The Impact (Benefits) of ICT on Healthcare Delivery in the Hospital}

The ultimate goal for evaluating the implemented system is to improve healthcare delivery. This research deems it expedient to assay the overall impact ICT renders to health care service delivery in the facility and the benefits the said facility reckons to achieve. The success of the hospital as an organizational entity chalked could be attributed to a number of contextualized and institutional factors [23]. From the research findings, the significant impact of the system included reduced workload among users, improvement in patients' waiting time, minimized mistakes which were an inherent feature of the paper-based records-keeping system. It has also been established that patients waiting time has significantly improved and there has also been drastic reduction in missing patients' records and folders as a result of unique coding cells offered by the EHR system. The implemented EHR in advancing up-to-date effective and efficient records keeping in healthcare delivery is consistent with the findings carried out by [24].

\subsection{Barriers to the Application of ICT Resources}

In spite of the myriad benefits associated with the ICT and health care delivery, the inherent challenges that gainsay the operationalization of the system cannot be overlooked. Majority of the respondents representing $64 \%$ agreed to the fact that lack of proper training could be a barrier to the effective use of ICT application. However, $72 \%$ bemoaned lack of ICT infrastructure coupled with that insufficient knowledge in ICT applications could impede the impact of ICT in quality service delivery. The above results are in total agreement with the study that stated that physicians as well as the patients have been found to have insufficient skills and technical knowledge in dealing with ICT innovations, which has resulted in resistance in the implementation of ICT initiatives in healthcare [25].

Nonetheless, $46 \%$ of the study participants agreed to the fact that one of the most noticeable challenges has to do with intermittent power supply.

Because of the unreliability of power supply by the Electricity Company of Ghana as a result of current loading-shedding exercise, the facility is unable to rely on constant energy supply in the country. It was also revealed from the responses that $70 \%$ agreed to the fact that failure or damage of software and hardware of ICT equipment could compromise the smooth running of the implemented system. The findings above affirm the fact that without electricity, it is impossible to successfully adopt ICT resources and this same reason applies to breakdown and failure of equipment. The situation is very alarming as it compromises the quality of healthcare delivery in the country as bemoaned by [26]. The above findings are consistent with similar studies carried out by [15] in 
Ghana.

The findings revealed that the IT infrastructure in most Ghanaian hospitals are woefully inadequate to contain the fully functionality of ICT systems. One of the problems also has to do with poor ICT network concerns. The facility lack proper Internet infrastructure and in most cases when there is availability of Internet connectivity, the network is most at times slow and with exorbitant prices for Internet access in African countries which tells of a gloomy picture for the poorer African countries.

\section{Conclusions}

The primary objective of the study was to assess the effects of Information and Communication Technology (ICT) on health service delivery at Tafo Government Hospital. Generally, the respondents had appreciable knowledge and attitude towards ICT use as they rated their skills as good. However, the study limitation had to do with the researcher's acquaintance with the hospital and the district, where perhaps there is bound to be a recall bias but tried as much as possible not to let it influence the research.

Therefore, conclusions drawn should be carefully considered for large scale adoption.

\section{Recommendations}

From the findings above, the study recommends the following:

1) Software applications are made more user-friendly by incorporating value added functions like automated reports, prompts and alerts.

2) Explore alternative sources of power supply for example solar or wind power.

3) Ministry of Health formulates policies that provide the structures for implementation of ICT in health care institutions in Ghana.

\section{Acknowledgements}

We are grateful to the health management team of Tafo Government hospital and cooperative respondents

\section{Conflicts of Interest}

The authors declare no conflicts of interest regarding the publication of this paper.

\section{References}

[1] Gour, N. and Srivastava, D. (2010) Knowledge of Computer among Healthcare Professionals of India, a Key toward e-Health. Telemedicine Journal and e-Health, 16, 957-962.

[2] Rodrigues, J. (2014) Advancing Medical Practice through Technology: Applications for Healthcare Delivery, Management, and Quality. Medical Information Science Reference/IGI Global, Hershey, PA. 
[3] Guah, M.W. (2011) Healthcare Delivery Reform and New Technologies, Organisational Initiatives. Medical Information Science Reference Hershey, PA. https://doi.org/10.4018/978-1-60960-183-6

[4] Burney, A., Mahmood, N. and Abbas, Z. (2010) Information and Communication Technology in Healthcare Management Systems: Prospects for Developing Countries. International Journal of Computer Applications, 4, 27-32. https://doi.org/10.5120/801-1138

[5] Arendt, L. (2013) Barriers to ICT Adoption in SMEs: How to Bridge the Digital Divide? Journal of Systems and Information Technology, 10, 93-108. https://doi.org/10.1108/13287260810897738

[6] Goel, S. (2014) Textbook of Hospital Administration. Elsevier Health Sciences, APAC, London.

[7] Housego, A.O. and Brien, T. (2012) Delivery of Public Services by Non-Government Organisations. Australian Journal of Public Administration, 71, 211-220. https://doi.org/10.1111/j.1467-8500.2012.00765.x

[8] World Health Organization (2014) E-Health. http://www.who.int/topics/ehealth/en/

[9] Khan, S.Z., Shahid, Z., Hedstrom, K. and Andersson, A. (2012) Hopes and Fears in Implementation of Electronic Health Records in Bangladesh. The Electronic Journal of Information Systems in Developing Countries, 54, 1-18. https://doi.org/10.1002/j.1681-4835.2012.tb00387.x

[10] Bedeley, R., T. and Palvia, P. (2014) Study of the Issues of E-Health Care in Developing Countries, the Case of Ghana. Twentieth Americas Conference on Information Systems, Savannah, 34.

[11] Kenyanya, J. (2015). Issues Affecting Healthcare in Kenya and Sub-Saharan Africa. Health Education Systems, 41-58.

[12] Agarwal, R. and Prasad, J. (2013) The Role of Innovation Characteristics and Perceived Voluntaries in the Acceptance of Information Technologies. Decision Sciences, 28, 557-582. https://doi.org/10.1111/j.1540-5915.1997.tb01322.x

[13] Anon, C. (2010) A Draft Policy for Harmonization of E-Health Initiatives in Africa. http://goo.gl/qsIYfA

[14] Qureshi, Q.A., Shah, B., Najeebullah, Kundi, G.M., Nawaz, A., Miankhel, A.K., Chishti, A.K. and Qureshi, N.A. (2013) Infrastructural Barriers to e-Health Implementation in Developing Countries. European Journal of Sustainable Development, 2, 163-170. https://doi.org/10.14207/ejsd.2013.v2n1p163

[15] Achampong, E. and Pereko, K.A. (2010) Computer Skills and the Training of Medical Respondents in a Ghanaian Medical School. Electronic Journal of Health Informatics, 5, e12. http://www.ejhi.net

[16] Bukachi, F. and Walsh, P. (2012) Information Technology for Heath in Developing Countries. Chest, 132, 1624-1630. https://doi.org/10.1378/chest.07-1760

[17] Ludwig, W., Wolf, K.H., Duwenkamp, C., Gusew, N., Hellrung, N., Marschollek, M., Wagner, M. and Haux, R. (2012) Health-Enabling Technologies for the Elderly-An Overview of Services Based on a Literature Review. Computer Methods and Programs in Biomedicine, 106, 70-78. https://doi.org/10.1016/j.cmpb.2011.11.001

[18] Omary, Z., Lupiana, D., Mtenzi, F. and Wu, B. (2009) Challenges to E-Healthcare Adoption in Developing Countries: A Case Study of Tanzania. First International Conference on Networked Digital Technologies, Ostrava. https://doi.org/10.1109/NDT.2009.5272067 
[19] Nyella, E. and Mndene, M. (2010) Power Tension in Health Information System Integration in Developing Countries: The Need for Distributed Control. Electronic Journal of Information Systems in Developing Countries, 43, 1-19. https://doi.org/10.1002/j.1681-4835.2010.tb00308.x

[20] Koehler, N., Vujovic, O. and McMenamin, C. (2013) Healthcare Professionals' Use of Mobile Phones and the Internet in Clinical Practice. Journal of Mobile Technology in Medicine, 2, 9-10. https://doi.org/10.7309/jmtm.2.1.2

[21] Gund, A., Lindecrantz, K., Schaufelberger, M., Patel, H. and Sjoqvist, B.A. (2012) Attitudes among Healthcare Professionals towards ICT and Home Follow-Up in Chronic Heart Failure Care. BMC Medical Informatics and Decision Making, 12, Article No. 138. https://doi.org/10.1186/1472-6947-12-138

[22] Adeleke, I. Erinle, A. and Ndana, T. (2015) Health Information Technology in Nigeria Stakeholders Perspectives of Nationwide Implementations and Meaningful Use of the Emerging Technology in the Most Populous Black Nation. American Journal of Health Research Special Issue, 3 17-24. https://doi.org/10.11648/j.ajhr.s.2015030101.13

[23] Shekelle, P. Morton, S.C. and Keeler, C. (2006) Costs and Benefits of Health Information Technology (Report). Evidence Reports/ Technology Assessments, 132, 1-71. https://doi.org/10.23970/AHRQEPCERTA132

[24] Sood, S., Nwabueze, S.N., Mbarika, V.W.A., Prakash, N., Chatterjee, S., Ray, P. and Mishra, S. (2008) Electronic Medical Records: A Review Comparing the Challenges in Developed and Developing Countries. Proceedings of the 41 st Annual Hawaii International Conference on System Sciences, Waikoloa, HI, 7-10 January 2008, 248-248. https://doi.org/10.1109/HICSS.2008.141

[25] Zerriffi, H. (2011) Rural Electrification, Strategies for Distributed Generation. Springer, Heidelberg. https://www.mdpi.com/journal/sustainability

[26] Adu, B. (2013) Accra Hospitals Reeling from Power and Water Shortages. Myjoyonline. http://edition.myjoyonline.com/pages/news/201302/101106.php 